\title{
Zum 75. Geburtstag von Wilhelm Weitz
}

Wilhelm Weitz wurde am 5. Mai I88I in Bad Pyrmont als Sohn des allgemein geachteten Arztes Dr. Carl Weitz geboren. Er brachte seine Studienjahre in Göttingen, Tübingen, Berlin und Kiel zu. Nach seinem Staatsexamen arbeitete er an der Kieler Medizinischen Universitäts-Klinik unter Quincke. Die damalige Art der klinischen Ausbildung, in der der Chef mit seinen Assistenten jeden neuen Patienten vom Kopf bis zu den Füssen gründlich untersuchte, hat bei Weitz ein Fundament hinterlassen, in dem die genaue und systematische unmittelbare Beobachtung des Patienten immer den ersten Platz einnahm. Danach kam Weitz als Sekundärarzt an das Krankenhaus St. Georg in Hamburg, wo er unter Deneke arbeitete, mit dem ihn eine jahrzehntelange Freundschaft verband. I9I 2 wurde Weitz Oberarzt an der

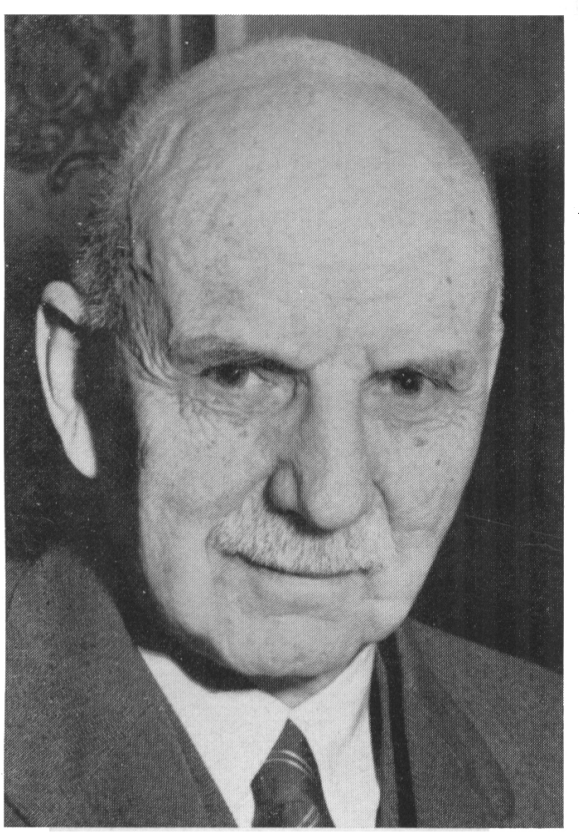

Medizinischen Klinik in Tübingen unter Otfried Müller. Im folgenden Jahre konnte er seine Habilitationschrift über « Experimentelle Untersuchungen über die Veränderungen des Elektrokardiogramms bei Abänderung der Herzarbeit » vorlegen. Ein lebhaftes Interesse für die Kardiologie, das ihn klinische Fragen mit methodischem Geschick fruchtbar anpacken liess, hat ihn seither nicht mehr verlassen. Der I. Weltkrieg, der Weitz als leitenden Internisten eines württembergischen Feldlazarettes sah, konnte den für wissenschaftliche Tätigkeit prädestinierten Geist von Weitz nur vorübergehend von seinem erwählten Feld abhalten. In den Jahren nach Kriegsende wurden die Probleme, die ihn nie losgelassen hatten, mit verdoppelter Energie wieder aufgenommen. 35 Arbeiten mit ungewöhnlich vielseitigen Fragestellungen hatte Weitz bis zum Jahre I92 I aufzuweisen, als er seine erste humangenetische Abhandlung publizierte, eine sehr gründliche Studie über die Vererbung der Muskeldystrophie.

In der damaligen Zeit, als in den Köpfen der meisten Mediziner noch die unklarsten Vorstellungen von Vererbung herrschten, war die Weitzsche Arbeit eine rühmliche Ausnahme. Seine Diskussion der Bedeutung der Mutationen, der Häufigkeit der Verwandtenehen, der Heterogenie der Erbleiden, usw., mutet erstaunlich modern 
an. Wenig später begann Weitz die Erbfaktoren bei der essentiellen Hypertension zu studieren. Mit diesen Untersuchungen ist er besonders bekannt geworden. Das Interesse für Vererbungsfragen führte ihn zur Zwillingsforschung. Mit Siemens kann Weitz als der Begründer der Zwillingspathologie gelten. Im Jahre I924 legte Weitz seine ersten umfassenden Berichte vor. Bereits 1923 hatte er seinen damaligen Assistenten v. Verschuer für die Zwillingsforschung begeistern können. Ueber die Weiterentwicklung dieser Schule der Zwillingsforschung braucht wohl für die Leser der Acta geneticae medicae nichts gesagt zu werden. Weitz wusste nun die Zwillingsforschung in guten Händen und konnte sich persönlich wieder neuen Fragen zuwenden, und zwar der Motorik der Organe mit glatter Muskulatur. Hier stellte er eine Reihe neuartiger Versuche an, deren interessante Ergebnisse zu Unrecht etwas in Vergessenheit geraten sind. 1927 wurde Weitz Leiter der Inneren Abteilung des Städtischen Krankenhauses Stuttgart-Cannstatt. Auch hier setzte er seine Forschungen fort. Insbesondere baute er die Zwillingsuntersuchungen aus, wovon zahlreiche Arbeiten seiner Schüler aus der damaligen Zeit zeugen. I936 nahm Weitz den Ruf als Professor der Inneren Medizin und Direktor der 2. Medizinischen Universitäts-Klinik Hamburg Eppendorf an. Dort hielt er neben einer Vorlesung über innere Medizin eine über Vererbungslehre. Am Eppendorfer Krankenhaus wurde ein Zwillings-Institut gegründet, dessen Kartothek Photographien und Krankengeschichten von 15.000 Zwillingspaaren enthielt, als es im Jahre I943 durch einen Bombenangriff völlig zerstört wurde. Für Weitz war dies ein schwerer Schlag. Alle bisherigen Publikationen aus dem Gebiet der Zwillingsforschung waren für ihn nur wie frühe Früchte vor der grossen Ernte gewesen, für die er jahrelang den Boden bestellt und gesät hatte. Die erhoffte wissenschaftliche Ernte war nun plötzlich und sinnlos vernichtet. Aber Weitz wurde darüber nicht verbittert. Er hat nie sich selbst und sein Werk im Mittelpunkt gesehen. Und viel mehr als an dem Schlag, der ihn persönlich betraf, litt er an der Sinnlosigkeit des ganzen Krieges, dessen Unrecht er tief empfand. Zwei Jahre später, mit dem Ende des Krieges, wurde ihm unter entehrenden Umständen sein Tätigkeitsfeld genommen. Niemand, der ihn persönlich kannte, konnte die Gründe hierfür verstehen. Weitz war in der Hitler-Zeit stets eine absolut integre Persönlichkeit geblieben. Aber I945 schien denjenigen, die nicht tiefer blickten, durch die unmenschliche Doktrin und Praxis des Nationalsozialismus die Erbbiologie suspekt zu sein. Weitz brachte es fertig, über der Sache zu stehen, die verhängnisvolle Verkettung zu begreifen und den Mut nicht sinken zu lassen. Freunde, die ihn in dieser Zeit besuchten, um ihm Mut zuzusprechen, haben ihn nie klagen hören, sondern konnten, durch sein Beispiel gestärkt, selbst getröstet von ihm gehen. Er arbeitete unter den schwierigsten Lebensumständen ungebrochen weiter. Im Jahre I949 erschienen eine Monographie über Hypotonie und die zweite Auflage seines Buches «Die Vererbung innerer Krankheiten ». Als Weitz wieder rehabilitiert und erneut in den Kreis der Fakultät aufgenommen wurde, war das für alle Beteiligten nur ein selbstverständlicher Akt der Gerechtigkeit. Seitdem hat Weitz 12 weitere Arbeiten publiziert. Jetzt, in seinem 76. Lebensjahr, bereitet er eine grössere Studie über die Aetiologie des akuten Rheumatismus vor, zu der er seit Jahren Material gesammelt hat. Weitz ist nie ein Mann 
gewesen, der viel Aufhebens von sich machte. Seine Leistungen und Erfolge haben ihm nichts von seiner natürlichen Bescheidenheit genommen. In dem Fünfundsiebzigjährigen findet man einen Menschen, der jene seltene Höflichkeit des Herzens besitzt, die wahre Anteilnahme und echtes Zuhören möglich macht. Dies ist wohl einer der wesentlichen Gründe dafür, dass Weitz einen ungewöhnlich grossen und treuen Kreis von Freunden hat. Ohne Weitz und seine Schüler wäre die Zwillingsforschung nicht das, was sie heute ist.

L. GEDDA 